\title{
G semsam \\ The effect of air bubble position on ART outcome in frozen-thawed blastocyst transfer
}

\section{Tingting Yang}

Guangdong Medical College - Dongguan Campus https://orcid.org/0000-0002-3623-7080

Bo Chen ( $\square$ bob_72@163.com )

Guangdong Medical College - Dongguan Campus https://orcid.org/0000-0002-1107-342X

\section{Xiaoyan Sun}

Department of Reproductive Center,SSL central hospital of Dongguan City

\section{Qingyang Li}

Department of Reproductive Center,SSL Central hospital of Dongguan City

\section{Qiumei Li}

Department of Reproductive Center,SSL Central hospital of Dongguan City

\section{Xuemei Chen}

Department of Reproductive Center,SSL Central hospital of Dongguan City

\section{Li Zhao}

Department of Reproductive Center,SSL Central hospital of Dongguan City

\section{Ruihua Pan}

Department of Reproductive Center,SSL Central hospital of Dongguan City

\section{Research}

Keywords: Embryo transfer, Blastocyst, Frozen-thawed, Air bubble, Clinical pregnancy, Live Birth

Posted Date: November 15th, 2021

DOI: https://doi.org/10.21203/rs.3.rs-1059586/v1

License: (c) (1) This work is licensed under a Creative Commons Attribution 4.0 International License.

Read Full License 


\section{Abstract \\ Background}

So far, only few literatures have studied the relationship between blastocyst transfer position and ART outcomes, and the conclusions are still controversial. Our study is to evaluate the effect of air bubble position on ART outcome and to find the optimal embryo transfer position in frozen-thawed blastocyst transfer.

\section{Methods}

This study included a retrospective cohort analysis of 399 frozen-thawed single blastocyst transfers ultrasound-guided performed between June 1, 2017 and November 30, 2020. All of the women scheduled for frozen-thawed single blastocyst transfers ultrasound-guided. The primary outcome is clinical pregnancy rate and the secondary outcome is live birth rate. Statistical analyses were conducted using One-way Anova, Kruscal Whallis $\mathrm{H}$ test, chi-square test and Smooth curve fitting.

\section{Results}

When BFD was less than $19 \mathrm{~mm}$, there was no significant change in clinical pregnancy rate as BFD increased ( $\mathrm{OR}=0.95,95 \% \mathrm{Cl}: 0.89$ to $1.02, \mathrm{P}=0.1373$ ); when $\mathrm{BFD}$ was more than $19 \mathrm{~mm}$, the clinical pregnancy rate decreased by $16 \%$ for every $1 \mathrm{~mm}$ increase in BFD (OR $=0.84,95 \% \mathrm{Cl}: 0.72$ to $0.98, \mathrm{P}=$ 0.0363). The effect of BFD on live birth rate were similar to that on clinical pregnancy rate, the inflection point was $19 \mathrm{~mm}$, when BFD was more than $19 \mathrm{~mm}$, the live birth rate decreases by $58 \%$ for every $1 \mathrm{~mm}$ increase in $\mathrm{BFD}(\mathrm{OR}=0.42,95 \% \mathrm{Cl}: 0.21$ to $0.86, \mathrm{P}=0.0174)$

\section{Conclusions}

The ideal pregnancy outcome can be achieved within $19 \mathrm{~mm}$ from uterus fundus after single blastocyst transfer, The clinical pregnancy and live birth at a distance of more $19 \mathrm{~mm}$ from the uterus fundus have a cliff-like downward trend.

\section{Introduction}

Embryo transfer (ET) is one of the most critical factors affecting assisted reproductive technology (ART). Many factors affecting embryo transfer are also related to the success of ART, such as catheter type, catheter loading technology, ultrasound technology [1-5]. During embryo transfer, we can clearly see the position of the catheter tip and the air bubbles by ultrasound. The position of the air bubble is an important indicator of the embryo position $[6,7]$. 
There have been lots of studies exploring the relationship between embryo transfer position and ART outcome [8-11]. Most of literature have shown that the location of cleavage embryos cannot be too close to the uterus fundus, nor too far from the uterus fundus, and the middle of the uterine cavity is the best position to place the embryos for optimal ART outcome [12-14]. In addition, in the ASRM standard embryo transfer protocol template, a committee suggested that the tip of the catheter should be placed in the upper or center of the uterine cavity (more than $1 \mathrm{~cm}$ from the fundus of the uterus) and then released the embryos, which can optimize the pregnancy rate [15].

In recent years, studies have shown that selective single embryo transfer is the most effective method to reduce the risk of multiple pregnancy and the related risks to the mother and child after in vitro fertilization, while maintaining the overall pregnancy rate [16-18]. Hence, blastocyst transfer has become a common practice in IVF [19]. However, only a small part of the studies existed exclusively analyzing the influence of air bubble position on ART outcome in blastocyst transfer [20]. Thus, it is still unknown where is the best embryo position in blastocyst transfer and whether it is consistent with cleavage embryo transfer. Therefore, this study aims to explore the effect of air bubble position on ART outcome and to find the optimal embryo transfer position in frozen-thawed blastocyst transfer.

\section{Materials And Methods Participants}

This study included a retrospective cohort analysis of 399 frozen-thawed embryo transfers (FET) ultrasound-guided embryo transfers performed in the reproductive center of SSL Central hospital of Dongguan City which is affiliated Southern medical university, China, between June 1, 2017 and November 30, 2020. Written informed consent was obtained from all patients.

The study included all women with infertility undergoing frozen-thawed cycle transfer of single blastocyst. The criteria used to exclude patients from the study were the following: (i) women of 40 years or above, (ii) difficulty of ET, (iii) presence of hydrosalpinx, (iv) the embryo flashes were not visualized, (v) cycle cancellation, (vi) endometrial thickness was $<7 \mathrm{~mm}$.

\section{Assisted Reproduction Procedures}

We performed endometrial preparation and FET in natural cycles, stimulation cycles, or hormone therapy cycles. In all women with regular menstrual cycles, FET was performed first in a natural cycle. From day 12 on, follicle growth was monitored by means of serum hormones and transabdominal ultrasound and women were regularly monitored every 2 days. When the dominant follicle diameter was $>16 \mathrm{~mm}$, endometrial thickness was $\geq 8 \mathrm{~mm}, E_{2}>150 \mathrm{pg} / \mathrm{mL}, \mathrm{P}<1.5 \mathrm{ng} / \mathrm{mL}$, a bolus of urinary hCG $(5,000 \mathrm{IU})$ was given to induce ovulation. Exogenous $P$ supplementation (dydrogesterone $40 \mathrm{mg} / \mathrm{d}$; Duphaston, Abbott Biologics, United States) was started after 5 days, and then blastocyst transfer was performed. 
The preparation of artificial endometrium included sequential administration of $E_{2}$ valerate and injection of progesterone. In short, $2 \mathrm{mg}$ of $\mathrm{E}_{2}$ valerate was taken at least twice daily for 14 to 16 days, and adjust the dose according to the endometrial thickness measured by vaginal ultrasound. If the endometrial thickness was $\geq 7 \mathrm{~mm}, E_{2}>150 \mathrm{pg} / \mathrm{mL}, P<1.5 \mathrm{ng} / \mathrm{mL}$, then progesterone injection would be started. Progesterone was injected daily at a dose of $20 \mathrm{mg}$, and FET was performed five days later. Each woman was transferred one blastocyst. After pregnancy, luteal phase support continued until 10 weeks of gestation.

The thawing process was performed by vitrification. After thawed, the embryos were transferred into G-2 Plus culture medium, and then cultured in a $\mathrm{CO}_{2}$ incubator for 1 to 2 hours and transferred. The distance between the air bubble (hyperechogenic spot) and the fundal endometrial surface (embryo-fundus distance, EFD) was measured by transvaginal US when the transfer catheter had been retracted completely for a few seconds.

For the analysis, the women were divided into four groups based on air bubble-uterine fundus distance (BFD): Group 1 included 59 blastocyst transfers in which BFD is less than $10 \mathrm{~mm}$. Group 2 consisted of 225 blastocyst transfers in which BFD is $10 \mathrm{~mm}$ or more and less than $15 \mathrm{~mm}$. Group 3 included 90 blastocyst transfers in which BFD is $15 \mathrm{~mm}$ or more and less than $20 \mathrm{~mm}$. Group 4 consisted of 25 blastocyst transfers in which BFD is $20 \mathrm{~mm}$ or more.

\section{Embryo Transfer}

After placing the woman with moderately full bladder in the lithotomy position, expose the cervix with a double valve speculum. Clean the mucus in the cervical canal with a sterile cotton swab immersed in the medium. Place the embryo in the atraumatic Cook Sydney embryo transfer catheter (Cook Medical, IN, USA), by using the "three-drop technique". Firstly, an air bubble was loaded into the catheter. Then, $20 \mu \mathrm{L}$ of medium was aspirated into the catheter and place the embryo in the smallest possible medium. The second air bubble was then loaded into the catheter. Finally, aspirate enough medium to bring the total volume to $30 \mu \mathrm{L}$. The outer catheter was first inserted into the cervical canal. Once the guide was positioned before or after the internal os, the inner catheter was placed through the outer catheter. Place the tip of the inner catheter in place. Gently release the medium containing the blastocyst into the uterine cavity. The catheter was slowly withdrawn and examined by the same embryologist under a stereomicroscope to ensure that there were no blastocyst retained. After the operation, the patient remained supine for approximately 30 minutes.

\section{Outcome Measures}

Data collected included age, BMI, type of infertility, infertility duration, main cause of infertility, AMH, ART way, times of previous embryo transferred, protocol, blastocyst score, and multinucleation, the levels of Estrogen and progesterone on endometrial transformation day, endometrial thickness on day of ET, and cycle outcome. 
The primary outcome of the study was the clinical pregnancy rate per cycle. Secondary outcome was the live birth rate. A clinical pregnancy was defined as the presence of a fetal sac visualized by transabdominal ultrasound examination at 6-8 weeks of amenorrhoea. Live birth was defined as the delivery of a living child.

\section{Statistical Analysis}

Continuous variables were presented as Mean \pm SD (normal distribution), categorical variables were presented as N (\%). One-way Anova (normal distribution), Kruscal Whallis $\mathrm{H}$ (skewed distribution) test, and chi-square test (categorical variable) were used to determine the statistical differences in the mean and proportion between groups.Smooth curve fitting was used to identify the non-linear relationships between embryo transfer position and clinical pregnancy rate. The method on how to use smooth curve fitting has been described in detail by Motulsky et al.[21]. If the non-linear correlation was observed, segmented regression model, LRT test (likelihood ratio test, to compare the difference between Model I and Model II) and Bootstrap resampling method were performed to calculate the threshold effect of the BFD on clinical pregnancy rate. When the ratio between BFD and clinical pregnancy rate appears obvious in smoothed curve, recursive method calculates automatically the inflection point, where the maximum model likelihood will be used [22].The present study listed non-adjusted models and multivariate adjusted models. Based on the recommendation of STROBE statement, we showed unadjusted, minimally adjusted analysis results, and results from a fully adjusted analysis.

All of the analyses were performed with the statistical software packages $\mathrm{R}$ (http://www.R-project.org, The R Foundation) and EmpowerStats (http://www.empowerstats.com, X\&Y Solutions, Inc., Boston, MA). $P$ values less than 0.05 (two-sided) were considered statistically significant.

\section{Results}

Baseline characteristics were listed in Table 1. The number of the women in the four subgroups was 59, $225,90,25$ respectively. The four subgroups were no significant difference in terms of age, BMI, duration of infertility, type of infertility, main cause of infertility, times of previous embryo transferred, $A M H, E_{2}$ and $P$ levels, endometrial thickness on day of ET (in millimeters), ART way, protocol and live birth rate $(P>0.05)$. There were significant differences in clinical pregnancy rate among the four subgroups $(P<0.05)$. 
Table 1

Patients' baseline characteristics and clinical parameters.

\begin{tabular}{|c|c|c|c|c|c|}
\hline \multirow[t]{2}{*}{ Variables } & \multicolumn{4}{|l|}{$\mathrm{BFD}(\mathrm{mm})$} & \multirow{2}{*}{$\begin{array}{l}P \\
\text { value }\end{array}$} \\
\hline & $\begin{array}{l}\text { Group } 1 \\
<10\end{array}$ & $\begin{array}{l}\text { Group } 210 \\
\text { to }<15\end{array}$ & $\begin{array}{l}\text { Group } 315 \\
\text { to }<20\end{array}$ & $\begin{array}{l}\text { Group } 4 \\
\geq 20\end{array}$ & \\
\hline No. of participants & 59 & 225 & 90 & 25 & \\
\hline Age $(y)$ & $\begin{array}{l}31.14 \pm \\
4.32\end{array}$ & $30.99 \pm 4.11$ & $31.02 \pm 4.31$ & $\begin{array}{l}31.44 \pm \\
4.76\end{array}$ & 0.962 \\
\hline BMI $\left(\mathrm{kg} / \mathrm{m}^{2}\right)$ & $\begin{array}{l}21.54 \pm \\
3.27\end{array}$ & $21.66 \pm 3.16$ & $21.33 \pm 3.28$ & $\begin{array}{l}22.34 \pm \\
3.04\end{array}$ & 0.549 \\
\hline Duration of infertility $(y)$ & $3.94 \pm 2.68$ & $3.74 \pm 2.76$ & $3.62 \pm 2.26$ & $3.60 \pm 2.25$ & 0.896 \\
\hline Type of infertility & & & & & 0.205 \\
\hline Primarily & $22(37.29 \%)$ & $101(44.89 \%)$ & $40(44.44 \%)$ & $7(28.00 \%)$ & \\
\hline Secondary & $37(62.71 \%)$ & $124(55.11 \%)$ & $50(55.56 \%)$ & 18 (72.00\%) & \\
\hline Main cause of infertility & & & & & 0.485 \\
\hline Tubal factor & $38(64.41 \%)$ & $154(68.44 \%)$ & $66(73.33 \%)$ & $20(80.00 \%)$ & \\
\hline Endometriosis & $0(0.00 \%)$ & $2(0.89 \%)$ & $3(3.33 \%)$ & $0(0.00 \%)$ & \\
\hline Ovulation disorder & $3(5.08 \%)$ & $9(4.00 \%)$ & $4(4.44 \%)$ & $0(0.00 \%)$ & \\
\hline Male factor & $15(25.42 \%)$ & $56(24.89 \%)$ & $15(16.67 \%)$ & $5(20.00 \%)$ & \\
\hline Unexplained & $3(5.08 \%)$ & $4(1.78 \%)$ & $2(2.22 \%)$ & $0(0.00 \%)$ & \\
\hline $\begin{array}{l}\text { times of previous embryo } \\
\text { transferred }\end{array}$ & & & & & 0.690 \\
\hline 1 & $39(66.10 \%)$ & $142(63.11 \%)$ & 58 (64.44\%) & $13(52.00 \%)$ & \\
\hline 2 & $10(16.95 \%)$ & $50(22.22 \%)$ & $20(22.22 \%)$ & $9(36.00 \%)$ & \\
\hline$\geq 3$ & $10(16.95 \%)$ & $33(14.67 \%)$ & $12(13.33 \%)$ & $3(12.00 \%)$ & \\
\hline $\mathrm{AMH}(\mathrm{ng} / \mathrm{mL})$ & $5.14 \pm 2.52$ & $5.31 \pm 3.04$ & $5.33 \pm 2.95$ & $5.58 \pm 2.04$ & 0.948 \\
\hline $\mathrm{E}_{2}$ level $(\mathrm{pg} / \mathrm{mL})$ & $\begin{array}{l}387.53 \pm \\
403.61\end{array}$ & $\begin{array}{l}319.67 \pm \\
383.02\end{array}$ & $\begin{array}{l}413.09 \pm \\
539.59\end{array}$ & $\begin{array}{l}291.52 \pm \\
234.73\end{array}$ & 0.267 \\
\hline P level (ng/ml) & $0.28 \pm 0.20$ & $0.28 \pm 0.21$ & $0.25 \pm 0.18$ & $0.23 \pm 0.19$ & 0.587 \\
\hline $\begin{array}{l}\text { Endometrial thickness } \\
(\mathrm{mm})\end{array}$ & $9.44 \pm 1.99$ & $10.04 \pm 1.88$ & $9.81 \pm 1.83$ & $\begin{array}{l}10.40 \pm \\
1.85\end{array}$ & 0.085 \\
\hline ART way & & & & & 0.205 \\
\hline IVF & $48(81.36 \%)$ & 175 (77.78\%) & 77 (85.56\%) & 17 (68.00\%) & \\
\hline
\end{tabular}




\begin{tabular}{|llllll|}
\hline Variables & \multicolumn{2}{l}{ BFD(mm) } & & & $\begin{array}{l}\text { P } \\
\text { value }\end{array}$ \\
\cline { 2 - 5 } & $\begin{array}{l}\text { Group 1 } \\
<10\end{array}$ & $\begin{array}{l}\text { Group 2 10 } \\
\text { to <15 }\end{array}$ & $\begin{array}{l}\text { Group 3 15 } \\
\text { to <20 }\end{array}$ & $\begin{array}{l}\text { Group 4 } \\
\geq 20\end{array}$ & \\
\hline ICSI & $11(18.64 \%)$ & $50(22.22 \%)$ & $13(14.44 \%)$ & $8(32.00 \%)$ & \\
\hline Protocol & & & & & 0.485 \\
\hline Natural cycle & $3(5.08 \%)$ & $18(8.00 \%)$ & $6(6.67 \%)$ & $3(12.00 \%)$ & \\
\hline Hormone therapy cycle & $46(77.97 \%)$ & $145(64.44 \%)$ & $53(58.89 \%)$ & $13(52.00 \%)$ & \\
\hline Stimulation cycle & $10(16.95 \%)$ & $62(27.56 \%)$ & $31(34.44 \%)$ & $9(36.00 \%)$ & \\
\hline Clinical pregnancy & $45(76.27 \%)$ & $153(68.00 \%)$ & $58(64.44 \%)$ & $10(40.00 \%)$ & 0.013 \\
\hline Abortion/Ectopic gestation & & & & & 0.058 \\
\hline Ectopic gestation & $2(4.35 \%)$ & $1(0.65 \%)$ & $0(0.00 \%)$ & $0(0.00 \%)$ & \\
\hline Abortion & $7(15.22 \%)$ & $27(17.53 \%)$ & $8(13.56 \%)$ & $5(45.45 \%)$ & \\
\hline Live birth & $37(82.22 \%)$ & $126(82.35 \%)$ & $51(87.93 \%)$ & $6(60.00 \%)$ & 0.192 \\
\hline
\end{tabular}

The results of univariate analysis were shown in Table 2 . Only age, $\geq 3$ times of embryo transferred, were significantly correlated with lower clinical pregnancy rate $(P<0.05)$. There was no significant correlation between other variables and clinical pregnancy rate $(P>0.05)$. Only age, secondary infertility were significantly correlated with lower live birth rate $(P<0.05)$. There was no significant correlation between other variables and live birth rate $(P>0.05)$. 
Table 2

Univariate analysis between the variables and ART outcomes.

\begin{tabular}{|c|c|c|c|c|c|}
\hline & \multirow[t]{2}{*}{ Statistics } & \multicolumn{2}{|l|}{ Clinical pregnancy } & \multicolumn{2}{|l|}{ Live birth } \\
\hline & & $\beta / O R(95 \% \mathrm{Cl})$ & $\begin{array}{l}P \\
\text { value }\end{array}$ & $\begin{array}{l}\beta / O R \\
(95 \% \mathrm{Cl})\end{array}$ & $\begin{array}{l}P \\
\text { value }\end{array}$ \\
\hline Age (y) & $\begin{array}{l}31.05 \pm \\
4.22\end{array}$ & $0.91(0.87,0.96)$ & 0.0005 & $\begin{array}{l}0.90(0.84 \\
0.98)\end{array}$ & 0.0132 \\
\hline $\mathrm{BMI}\left(\mathrm{kg} / \mathrm{m}^{2}\right)$ & $\begin{array}{l}21.61 \pm \\
3.19\end{array}$ & $0.96(0.90,1.03)$ & 0.2354 & $\begin{array}{l}0.98(0.89 \\
1.09)\end{array}$ & 0.7437 \\
\hline Duration of infertility (y) & $3.73 \pm 2.61$ & $0.95(0.88,1.03)$ & 0.1814 & $\begin{array}{l}1.04(0.91 \\
1.18)\end{array}$ & 0.5767 \\
\hline $\mathrm{AMH}(\mathrm{ng} / \mathrm{mL})$ & $5.30 \pm 2.89$ & $1.04(0.96,1.12)$ & 0.3584 & $\begin{array}{l}1.06(0.95 \\
1.20)\end{array}$ & 0.3012 \\
\hline \multicolumn{6}{|l|}{ Type of infertility } \\
\hline Primarily & $\begin{array}{l}170 \\
(42.61 \%)\end{array}$ & 1 & & 1 & \\
\hline Secondary & $\begin{array}{l}229 \\
(57.39 \%)\end{array}$ & $1.02(0.67,1.55)$ & 0.9429 & $\begin{array}{l}0.36(0.18, \\
0.75)\end{array}$ & 0.0064 \\
\hline \multicolumn{6}{|l|}{ Main cause of infertility } \\
\hline Tubal factor & $\begin{array}{l}278 \\
(69.67 \%)\end{array}$ & 1 & & 1 & \\
\hline Endometriosis & $5(1.25 \%)$ & $2.08(0.23,18.84)$ & 0.5161 & - & -- \\
\hline Ovulation disorder & $16(4.01 \%)$ & $1.14(0.39,3.38)$ & 0.8105 & - & - \\
\hline Male factor & $91(22.81 \%)$ & $1.17(0.70,1.94)$ & 0.5502 & $\begin{array}{l}1.74(0.76 \\
3.97)\end{array}$ & 0.1870 \\
\hline Unexplained & $9(2.26 \%)$ & $0.65(0.17,2.47)$ & 0.5264 & $\begin{array}{l}1.01(0.11 \\
9.34)\end{array}$ & 0.9904 \\
\hline \multicolumn{6}{|l|}{$\begin{array}{l}\text { times of previous embryo } \\
\text { transferred }\end{array}$} \\
\hline 1 & $\begin{array}{l}252 \\
(63.16 \%)\end{array}$ & 1 & & 1 & \\
\hline 2 & $89(22.31 \%)$ & $0.79(0.47,1.32)$ & 0.3749 & $\begin{array}{l}0.94(0.43 \\
2.07)\end{array}$ & 0.8790 \\
\hline$\geq 3$ & $58(14.54 \%)$ & $0.49(0.27,0.87)$ & 0.0153 & $\begin{array}{l}0.67(0.26 \\
1.70)\end{array}$ & 0.4025 \\
\hline $\mathrm{E}_{2}$ level $(\mathrm{pg} / \mathrm{mL})$ & $\begin{array}{l}349.90 \pm \\
422.65\end{array}$ & $1.00(1.00,1.00)$ & 0.2680 & $\begin{array}{l}1.01(0.11, \\
9.34)\end{array}$ & 0.9904 \\
\hline
\end{tabular}




\begin{tabular}{|c|c|c|c|c|c|}
\hline & \multirow[t]{2}{*}{ Statistics } & \multicolumn{2}{|l|}{ Clinical pregnancy } & \multicolumn{2}{|l|}{ Live birth } \\
\hline & & $\beta / O R(95 \% \mathrm{Cl})$ & $\begin{array}{l}P \\
\text { value }\end{array}$ & $\begin{array}{l}\text { B/OR } \\
(95 \% \mathrm{Cl})\end{array}$ & $\begin{array}{l}P \\
\text { value }\end{array}$ \\
\hline P level (ng/ml) & $0.27 \pm 0.20$ & $0.61(0.22,1.73)$ & 0.3551 & $\begin{array}{l}2.78(0.40 \\
19.21)\end{array}$ & 0.3006 \\
\hline $\begin{array}{l}\text { Endometrial thickness } \\
(\mathrm{mm})\end{array}$ & $9.92 \pm 1.89$ & $\begin{array}{l}1.06(0.95,1.19) \\
0.2950\end{array}$ & 0.2950 & $\begin{array}{l}0.93(0.78 \\
1.10)\end{array}$ & 0.4041 \\
\hline \multicolumn{6}{|l|}{ ART way } \\
\hline IVF & $\begin{array}{l}323 \\
(79.75 \%)\end{array}$ & 1 & & 1 & \\
\hline ICSI & $82(20.25 \%)$ & $0.97(0.58,1.61)$ & 0.9066 & $\begin{array}{l}1.05(0.64, \\
1.73)\end{array}$ & 0.8380 \\
\hline \multicolumn{6}{|l|}{ Protocol } \\
\hline Natural cycle & $29(7.16 \%)$ & 1 & & 1 & \\
\hline Hormone therapy cycle & $\begin{array}{l}257 \\
(63.46 \%)\end{array}$ & $1.29(0.59,2.81)$ & 0.5263 & $\begin{array}{l}1.21(0.55 \\
2.66)\end{array}$ & 0.6433 \\
\hline Stimulation cycle & $\begin{array}{l}119 \\
(29.38 \%)\end{array}$ & $1.50(0.65,3.46)$ & 0.3367 & $\begin{array}{l}0.80 \\
1.85)\end{array}$ & 0.5989 \\
\hline
\end{tabular}

To evaluate the relationship between BFD and ART outcome (clinical pregnancy and live birth), 3 models including crude model, minimally adjusted model and fully adjusted model were established in Table 3 . In crude model, BFD showed negative correlation with clinical pregnancy $(\mathrm{OR}=0.93,95 \% \mathrm{Cl}: 0.87$ to $0.98, \mathrm{P}$ $=0.011$ ). The result did not have obvious changes in 2 adjusted models. For the purpose of sensitivity analysis, BFD was also analyzed as categorical variable, and found that the same trend was observed as well. 
Table 3

Relationship between BFD and ART outcome in different models

\begin{tabular}{|c|c|c|c|c|c|c|}
\hline \multirow[t]{2}{*}{ Exposure } & \multicolumn{2}{|l|}{ Crude Model } & \multicolumn{2}{|c|}{$\begin{array}{l}\text { Minimally adjusted } \\
\text { model }\end{array}$} & \multicolumn{2}{|c|}{ Fully adjusted model } \\
\hline & $\beta / O R(95 \% \mathrm{Cl})$ & $\begin{array}{l}P \\
\text { value }\end{array}$ & $\beta / O R(95 \% \mathrm{Cl})$ & $\begin{array}{l}P \\
\text { value }\end{array}$ & $\beta / O R(95 \% \mathrm{Cl})$ & $\begin{array}{l}\mathrm{P} \\
\text { value }\end{array}$ \\
\hline \multicolumn{7}{|l|}{$\begin{array}{l}\text { Clinical } \\
\text { pregnancy }\end{array}$} \\
\hline $\mathrm{BFD}(\mathrm{mm})$ & $\begin{array}{l}0.92(0.87, \\
0.97)\end{array}$ & 0.0021 & $\begin{array}{l}0.93(0.87 \\
0.99)\end{array}$ & 0.0147 & $\begin{array}{l}0.93(0.87, \\
0.98)\end{array}$ & 0.0110 \\
\hline \multicolumn{7}{|l|}{$\mathrm{BFD}(\mathrm{mm})$} \\
\hline$<10$ & 1 & & 1 & & 1 & \\
\hline 10 to $<15$ & $\begin{array}{l}0.66(0.34 \\
1.28)\end{array}$ & 0.2205 & $\begin{array}{l}0.58(0.28 \\
1.20)\end{array}$ & 0.1435 & $\begin{array}{l}0.57(0.27 \\
1.17)\end{array}$ & 0.1270 \\
\hline 15 to $<20$ & $\begin{array}{l}0.56(0.27 \\
1.18)\end{array}$ & 0.1286 & $\begin{array}{l}0.55(0.24 \\
1.25)\end{array}$ & 0.1520 & $\begin{array}{l}0.54(0.24 \\
1.22)\end{array}$ & 0.1393 \\
\hline$\geq 20$ & $\begin{array}{l}0.21(0.08, \\
0.56)\end{array}$ & 0.0020 & $\begin{array}{l}0.21(0.07 \\
0.66)\end{array}$ & 0.0072 & $\begin{array}{l}0.20(0.06 \\
0.62)\end{array}$ & 0.0055 \\
\hline \multicolumn{7}{|l|}{ Live birth } \\
\hline $\mathrm{BFD}(\mathrm{mm})$ & $\begin{array}{l}0.99(0.91, \\
1.08)\end{array}$ & 0.8649 & $\begin{array}{l}1.01(0.92, \\
1.10)\end{array}$ & 0.9084 & $\begin{array}{l}1.00(0.91, \\
1.10)\end{array}$ & 0.9442 \\
\hline \multicolumn{7}{|l|}{$\mathrm{BFD}(\mathrm{mm})$} \\
\hline$<10$ & 1 & & 1 & & 1 & \\
\hline 10 to $<15$ & $\begin{array}{l}1.01(0.42, \\
2.41)\end{array}$ & 0.9839 & $\begin{array}{l}1.04(0.41 \\
2.69)\end{array}$ & 0.9282 & $\begin{array}{l}1.05(0.40 \\
2.72)\end{array}$ & 0.9274 \\
\hline 15 to $<20$ & $\begin{array}{l}1.58(0.52 \\
4.73)\end{array}$ & 0.4177 & $\begin{array}{l}1.76(0.54 \\
5.81)\end{array}$ & 0.3502 & $\begin{array}{l}1.71(0.52 \\
5.64)\end{array}$ & 0.3805 \\
\hline$\geq 20$ & $\begin{array}{l}0.32(0.07 \\
1.42)\end{array}$ & 0.1354 & $\begin{array}{l}0.33(0.06 \\
1.72)\end{array}$ & 0.1888 & $\begin{array}{l}0.31(0.06 \\
1.68)\end{array}$ & 0.1750 \\
\hline
\end{tabular}

We also used smooth fitting curves to explore the relationship between BFD and clinical pregnancy rate/live birth rate (Fig. 1/Fig. 2). We found that with the increase of BFD, both clinical pregnancy rate and live birth rate decreased. Table 4 and Table 5 presented the threshold effect analysis for relationship between BFD and clinical pregnancy rate/live birth rate. A inflection point was found and it's $19 \mathrm{~mm}$. After adjusting the variables including age, main cause of infertility, ART ways, times of previous embryo transferred, type of infertility, duration of infertility, BMI, AMH, protocol, endometrial thickness, embryo score and embryo multinucleation, we found that when BFD was less than $19 \mathrm{~mm}$, there is no significant change in clinical pregnancy rate and live birth rate as $B F D$ increased $(\mathrm{OR}=0.95,95 \% \mathrm{Cl}: 0.89$ to $1.02, \mathrm{P}=$ 
0.1373; and $\mathrm{OR}=1.06,95 \% \mathrm{Cl}$ : 0.96 to $1.17, \mathrm{P}=0.2665$; respectively); when BFD was more than $19 \mathrm{~mm}$, the clinical pregnancy rate decreases by $16 \%$ for each increase in BFD (OR $=0.84,95 \% \mathrm{Cl}: 0.72$ to $0.98, \mathrm{P}$ $=0.0363)$ and the live birth rate decreases by $58 \%$ for each increase in BFD (OR $=0.42,95 \% \mathrm{Cl}$ : 0.21 to $0.86, P=0.0174)$.

Table 4

Threshold Effect Analysis of BFD and clinical pregnancy rate using Piece-wise Linear Regression.

\begin{tabular}{|llll|}
\hline Inflection point of BFD $(\mathbf{m m})$ & OR & $95 \% \mathrm{Cl}$ & P value \\
\hline$<19$ & 0.95 & 0.89 to 1.02 & 0.1373 \\
$\geq 19$ & 0.84 & 0.72 to 0.98 & 0.0363 \\
\hline
\end{tabular}

Table 5

Threshold Effect Analysis of BFD and live birth rate using Piecewise Linear Regression.

\begin{tabular}{|llll|}
\hline Inflection point of BFD (mm) & OR & $95 \% \mathrm{Cl}$ & P value \\
\hline$<19$ & 1.06 & 0.96 to 1.17 & 0.2665 \\
\hline$\geq 19$ & 0.42 & 0.21 to 0.86 & 0.0174 \\
\hline
\end{tabular}

\section{Discussion}

Single blastocyst transfer occurs near the planting window, the endometrial receptivity is stronger, and can reduce the risk of multiple pregnancy[20,23,24], thus it has become the main trend of IVF-ET. However, most of the previous studies using catheter tip placement or bubble positioning to study the optimal embryo position mainly analyzed the IVF cycle of embryos with cleavage stage, and did not pay significant attention to blastocyst transfer.

This study explored the effect of air bubble position on ART outcome in frozen-thawed single blastocyst transfer. We found that the clinical pregnancy was significantly higher when the flash is less than $20 \mathrm{~mm}$ from the fundus of the uterus after blastocyst transfer, compared with more than $20 \mathrm{~mm}(P<0.05)$. Our results are consistent with the findings of a retrospective cohort study suggesting[20]. However, our study is contradictory to many studies that consider that the best results would be obtained when placing the embryo in the middle of the uterine cavity rather than near the uterus fundus[12-14]. It is important to note that we and the retrospective cohort study explored embryo transfer at the blastocyst stage[20], not at the cleavage stage[12-14].

In addition, the smooth curve fitting and threshold effect model showed that the closer the air bubble is from uterus fundus, the higher the clinical pregnancy rate. On the contrary, the air bubble position away from the uterus fundus resulted in a decrease in the clinical pregnancy rate and live birth rate. Especially when the distance between the air bubble and the uterus fundus $>19 \mathrm{~mm}$, the clinical pregnancy rate 
decreased significantly. Each time the distance between the air bubble and the uterus fundus increased by $1 \mathrm{~mm}$, the clinical pregnancy rate decreased by $16 \%(\mathrm{OR}=0.84,95 \% \mathrm{Cl}: 0.72$ to $0.98, \mathrm{P}=0.0363)$. When placing the blastocyst more than $19 \mathrm{~mm}$ away from the uterus fundus, live birth rate significantly lower than the uterus fundus $<19 \mathrm{~mm}$.

In recent years, studies have found that it is possible for the embryos to migrate in the uterine cavity after embryo transfer. Whether in the cleavage embryo stage or the blastocyst stage, most of the embryos moved to the fundus, and the clinical pregnancy rate of the group that moved to the fundus was higher than that of the stationary group and the group that moved to the cervix, which also proved the position near the uterine cavity central and fundus is indeed suitable for embryo transfer[23, 24]. Meanwhile, the location of the gestational sacs are mostly in the upper part of the uterine cavity in spontaneous conception(89.1\%) [25]. The frozen-thawed single blastocyst transfers are closer to the natural conception, without super-physiological hormones in the ovulation stimulation cycle and this may be another reason for better ART outcome was obtained when air bubble were observed near the uterus fundus after embryo transfer in this study.

Moreover, the fundal endometrium is more conducive to embryo implantation because of a lower endometrial wavelike activity and an increased endometrial tissue blood flow[26-28]. Some researchers oppose placing embryos too close to the fundal endometrium because they fear that uterine contractions caused by high replacement has a negative impact on ART outcome [29-31]. A retrospective study found that air bubbles moving towards the uterine fundus with ejection were associated with higher pregnancy rates [32]. Thus, this may prove a point, it does not touch the mucosa membrane during migration, it is still beneficial to place the embryo near uterine cavity central and the fundus[8]. In contrast, the farther the transfer position is from the fundus of the uterus, the lower the pregnancy rate, which may be associated with an increased risk of embryo expulsion from the uterine cavity [33].

There are some advantages to this research. First of all, in most other reports, the distance between air bubble and the uterus fundus was classified in $5 \mathrm{~mm}$ increments [12-14], which may result in errors caused by artificial grouping. We make up for this deficiency by using the smooth fitting curve and threshold effect model. Second, we have made adjustments to reduce interference from other factors. Third, this study explored the frozen-thawed blastocysts transfer, which was rarely discussed by previous researchers, and the result was different from that in fresh cleavage embryo transfer.

This study also has some limitations. Firstly, this is a retrospective study which makes many constraints unavoidable. Since there was no AMH testing project before 2016, the AMH data of some patients was missing. Besides, in this study, the position of the embryo is replaced by the position of the bubble, not the position of the embryo itself, which may also not necessarily be true. Lastly, morphometric characteristics of the cavity, such as geometric shape, size and rotation, were not observed in this study.

In conclusion, The clinical pregnancy and live birth at a distance of $19 \mathrm{~mm}$ from the uterus fundus have a cliff-like downward trend. Therefore, the ideal pregnancy outcome can be achieved within $19 \mathrm{~mm}$ from uterus fundus after single blastocyst transfer.

Page 12/19 


\section{Limitations And Extrapolation Potential To The Human Situation}

Since there was no AMH testing project before 2016, the AMH data of some patients was missing. Besides, morphometric characteristics of the cavity, such as geometric shape, size and rotation, were not observed in this study. This study explored the effect of air bubble position on ART outcome in frozenthawed blastocyst transfer and the results were different from those in cleavage embryo transfer.

\section{Conclusions}

The ideal pregnancy outcome can be achieved within $19 \mathrm{~mm}$ from uterus fundus after single blastocyst transfer, The clinical pregnancy and live birth at a distance of more $19 \mathrm{~mm}$ from the uterus fundus have a cliff-like downward trend.

\section{Abbreviations}

ART:Assisted Reproductive Technology;ET:Embryo transfer;FET:Frozen-thawed Embryo transfer;IVF:In vitro fertilization; $h C G$.Human chorionic gonadotropin;

BFD:bubble-uterine fundus distance;EFD:embryo-fundus distance;

AMH:Anti-Mullerian hormone

\section{Declarations}

\section{Ethics approval}

All procedures performed in studies involving human participants were based on the ethical standards of the institutional and national research committee, as well as the Helsinki Declaration of 1964 and its subsequent amendments or similar ethical standards. So this retrospective analysis doesn't need the approval from the institutional review board.

\section{Consent for publication}

All writers agreed to public the study

\section{Availability of data and material}

The data was collected from the reproductive center of SSL Central hospital of Dongguan City which is affiliated Southern medical university, China. All data are available from the corresponding author by request.

\section{Competing interests}

No conflict of interest need to be declared. 


\section{Funding}

This research was supported by Dongguan science and technology development project.囚project numbers 202050715024885区.

\section{Authors' contributions}

TT.Y participated in the study design, the statistical analysis and wrote the main parts of the manuscript. XY.S and XM.C participated in clinical diagnosis and treatment. QY.L and Z.L participated in embryo operation and performing scoring of the embryos. QM.L and RH.P participated in follow-up visit and collecting the data. B.C participated the study design, supervising the development of the manuscript and revised the manuscript for final approval.

\section{Acknowledgement}

The authors gratefully thank Dr. Xinglin Chen and Chi Chen of the Department of Epidemiology and Biostatistics, Empower U, X\&Y solutions Inc. in Boston for her contribution to the statistical support. The authors also acknowledge the medical staff who assisted with this research in each of the reproductive center of SSL Central hospital of Dongguan City which is affiliated Southern medical university, including Departments of Obstetrics and Gynecology and Reproductive Medicine Center.

\section{Author details}

${ }^{1}$ Department of Guangdong Medical University, Dongguan, 523808, China ${ }^{2}$ Department of Gynecology, SSL Central hospital of Dongguan City, Dongguan, 523321, China ${ }^{3}$ Department of Reproductive Center, SSL Central hospital of Dongguan City, Dongguan, 523321, China ${ }^{4}$ Department of Obstetrics, SSL Central hospital of Dongguan City, Dongguan, 523321, China

\section{References}

1.Abou-Setta AM, Al-Inany HG, Mansour RT, Serour GI, Aboulghar MA. Soft versus firm embryo transfer catheters for assisted reproduction: a systematic review and meta-analysis. Hum Reprod. 2005;20:311421. https://doi.org/10.1093/humrep/dei198

2.Buckett WM. A review and meta-analysis of prospective trials comparing different catheters used for embryo transfer. Fertil Steril. 2006;85:728-34.https://doi.org/10.1016/j.fertnstert.2005.08.031

3.Saldeen P, Abou-Setta AM, Bergh T, Sundström P, Holte J. A prospective randomized controlled trial comparing two embryo transfer catheters in an ART program. Fertil Steril. 2008;90:599-603. https://doi.org/10.1016/j.fertnstert.2007.06.085

4.Matorras R, Mendoza R, Expósito A, Rodriguez-Escudero FJ. Influence of the time interval between embryo catheter loading and discharging on the success of IVF. Hum Reprod. 2004;19:2027-30. 
5.lyoke CA, Ugwu GO, Ezugwu FO, Ajah LO, Mba SG. The role of ultrasonography in in-vitro fertilization and embryo transfer (IVF-ET). Niger J Med. 2013;22:162-170.

6.Krampl E, Zegermacher G, Eichler C, Obruca A, Strohmer H, Feichtinger. Air in the uterine cavity after embryo transfer. Fertil Steril 1995;63:366-70. https://doi.org/10.1016/s0015-0282(16)57370-1

7.Moreno V, Balasch J, Vidal E, Calafell JM, Civico S, Vanrell JA. Air in the transfer catheter does not affect the success of embryo transfer. Fertil Steril 2004;81: 136670.https://doi.org/10.1016/j.fertnstert.2003.09.060

8.Schoolcraft WB, Surrey ES, Gardner DK: Embryo transfer: techniques and variables affecting success. Fertil Steril 2001, 76:863-870. https://doi.org/10.1016/s0015-0282(01)02731-5

9.Pope CS, Cook EK, Arny M, Novak A, Grow DR. Influence of embryo transfer depth on in vitro fertilization and embryo transfer outcomes. Fertil Steril. 2004;81:518.https://doi.org/10.1016/j.fertnstert.2003.05.030

10.Moore DE, Soules MR, Klein NA, Fujimoto VY, Agnew KJ, Eschenbach DA. Bacteria in the transfer catheter tip influence the live-birth rate after in vitro fertilization. Fertil Steril. 2000;74:1118-24. https://doi.org/10.1016/s0015-0282(00)01624-1

11.Abou-Setta AM. What is the best site for embryo deposition? A systematic review and meta-analysis using direct and adjusted indirect comparisons. Reprod Biomed Online. 2007;14:6119.https://doi.org/10.1016/s1472-6483(10)61054-1

12.Rovei V, Dalmasso P, Gennarelli G, Lantieri T, Basso G, Benedetto C, et al. IVF outcome is optimized when embryos are replaced between 5 and $15 \mathrm{~mm}$ from the fundal endometrial surface: a prospective analysis on 1184 IVF cycles. Reprod Biol Endocrinol 2013;11:114.https://doi.org/10.1186/1477-7827-11114

13.Wang Y, Zhu Y, Sun Y, Di W, Qiu M, Kuang Y, et al. Ideal embryo transfer position and endometrial thickness in IVF embryo transfer treatment. Int J Gynaecol Obstet 2018;143:282-

8.https://doi.org/10.1002/ijgo.12681

14.Kwon, $\mathrm{H}$, Choi $\mathrm{DH}$, Kim EK. Absolute position versus relative position in embryo transfer: a randomized controlled trial. Reprod Biol Endocrinol 2015;13:78.https://doi.org/10.1186/s12958-015-0072-6

15.Alan Penzias, Kristin Bendikson, Samantha Butts, et al. ASRM standard embryo transfer protocol template: a committee opinion. Fertil Steril.2017,107(4): 897-

900.https://doi.org/10.1016/j.fertnstert.2017.02.108 
16.Criniti $A \bigotimes$ Thyer $A \bowtie C h o w ~ G \llbracket e t$ al. Elective single blastocyst transfer reduces twin rates without compromising pregnancy rates. Fertil Steril, 2005, 84(6): 1613-

1619.https://doi.org/10.1016/j.fertnstert.2005.06.035

17.Styer AK\Wright DL囚Wolkovich AM『et al. Single -blastocyst transfer decreases twin gestation without affecting pregnancy outcome. Fertil Steril, 2008, 89(6): 1702-

1708.https://doi.org/10.1016/j.fertnstert.2007.05.036

18.Khalaf Y『El-Toukhy T囚Coomarasamy A囚et al. Selective single blastocyst transfer reduces the multiple pregnancy rate and increases pregnancy rates $₫ a$ pre- and postintervention study. BJOG, 2008, 115(3): 385-390.https://doi.org/10.1111/j.1471-0528.2007.01584.x

19.Daimin W, jia-Yin L, Yun Sun,et al. Frozen versus fresh single blastocyst transfer in ovulatory women: a multicentre, randomised controlled trial. Lancet, 2019, 393(10178): 1310-

1318.https://doi.org/10.1016/S0140-6736(18)32843-5

20.Friedman BE, Lathi RB, Henne MB, Fisher SL, Milki AA. The effect of air bubble position after blastocyst transfer on pregnancy rates in IVF cycles. Fertil Steril. 2011;95:944947.https://doi.org/10.1016/j.fertnstert.2010.07.1063

21.Motulsky H, Christopoulos A. Fitting models to biological data using linear and nonlinear regression: a practical guide to curve fitting: Oxford University Press; 2004;12-47.

22.Liu S, Wang X, Lu Y, Li T, Gong Z, Sheng T, et al. The effects of intraoperative cryoprecipitate transfusion on acute renal failure following orthotropic liver transplantation. Hepatol Int. 2013;7:901-9. https://doi.org/10.1007/s12072-013-9457-9

23.Saravelos $\mathrm{SH}$, Wong AW, Chan $\mathrm{CP}$, Kong GW, Cheung LP, Chung $\mathrm{CH}$, et al. Assessment of the embryo flash position and migration with 3D ultrasound within 60 min of embryo transfer. Hum Reprod 2016;31:591-6.https://doi.org/10.1093/humrep/dev343

24.Cem Fıçıcıoğlu, Pınar Özcan, Melis G Koçer, Mert Yeşiladalı, Oya Alagöz, Gülçin Özkara. Effect of air bubbles localization and migration after embryo transfer on assisted reproductive technology outcome. Fertil Steril. 2018;109(2):310-314.e1.https://doi.org/10.1016/j.fertnstert.2017.10.032

25.Minami S, Ishihara K, Araki T. Determination of blastocyst implantation site in spontaneous pregnancies using three-dimensional transvaginal ultrasound. J Nippon Med Sch. 2003;70:2504.https://doi.org/10.1272/jnms.70.250

26.Lambers MJ, Dogan E, Lens JW, Schats R, Hompes PG. The position of transferred air bubbles after embryo transfer is related to pregnancy rate. Fertil Steril 2007;88:68-73.

https://doi.org/10.1016/j.fertnstert.2006.11.085 
27.Van Gestel I, IJland MM, Hoogland HJ, Evers JL. Endometrial wave-like activity in the non-pregnant uterus. Hum Reprod Update 2003;9:131-8. https://doi.org/10.1093/humupd/dmg011

28.Jinno M, Ozaki T, Iwashita M, Nakamura Y, Kudo A, Hirano H. Measurement of endometrial tissue blood ffflow: a novel way to assess uterine receptivity for implantation. Fertil Steril 2001;76:1168-74. https://doi.org/10.1016/s0015-0282(01)02897-7

29.Fanchin R, Righini C, Olivennes F, Taylor S, de Ziegler D, Frydman R. Uterine contractions at the time of embryo transfer alter pregnancy rates after in-vitro fertilization. Hum Reprod. 1998;13:1968-74. https://doi.org/10.1093/humrep/13.7.1968

30.Lesny P, Killick SR, Tetlow RL, Robinson J, Maguiness SD. Embryo transfer-can we learn anything new from the observation of junctional zone contractions? Hum Reprod. 1998;13:1540-6. https://doi.org/10.1093/humrep/13.6.1540

31. Woolcott R, Stanger J. Potentially important variables identified by transvaginal ultrasound-guided embryo transfer. Hum Reprod. 1997;12:963-6.https://doi.org/10.1093/humrep/12.5.963

32.Tiras B, Korucuoglu U, Polat M, Saltik A, Zeyneloglu HB, Yarali H. Effect of air bubble localization after transfer on embryo transfer outcomes. Eur J Obstet Gynecol Reprod Biol 2012;164:524.https://doi.org/10.1016/j.ejogrb.2012.05.025

33.Zhu L, Xiao L, Che HS, Li YP, Liao JT. Uterine peristalsis exerts control over ffluid migration after mock embryo transfer. Hum Reprod 2014; 29:279 - 285.https://doi.org/10.1093/humrep/det429

\section{Figures}




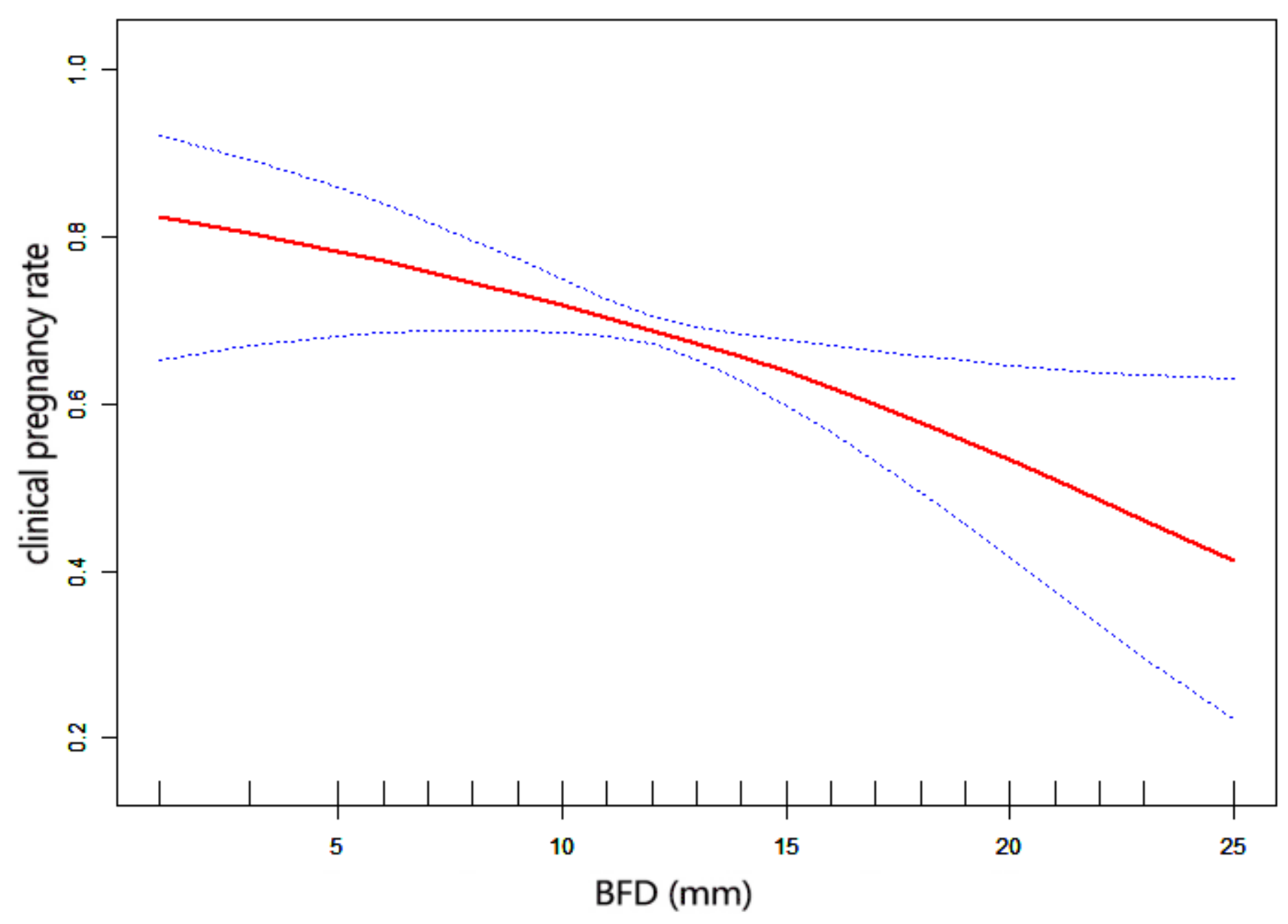

Figure 1

Association between BFD and clinical pregnancy rate. A threshold, nonlinear association between BFD and clinical pregnancy was found in a generalized additive model (GAM). Solid rad line represents the smooth curve fit between variables. Blue bands represent the $95 \%$ of confidence interval from the fit. All adjusted for age, main cause of infertility, ART ways, times of previous embryo transferred, type of infertility, duration of infertility, $\mathrm{BMI}, \mathrm{AMH}$, protocol, endometrial thickness, embryo score and embryo multinucleation. 


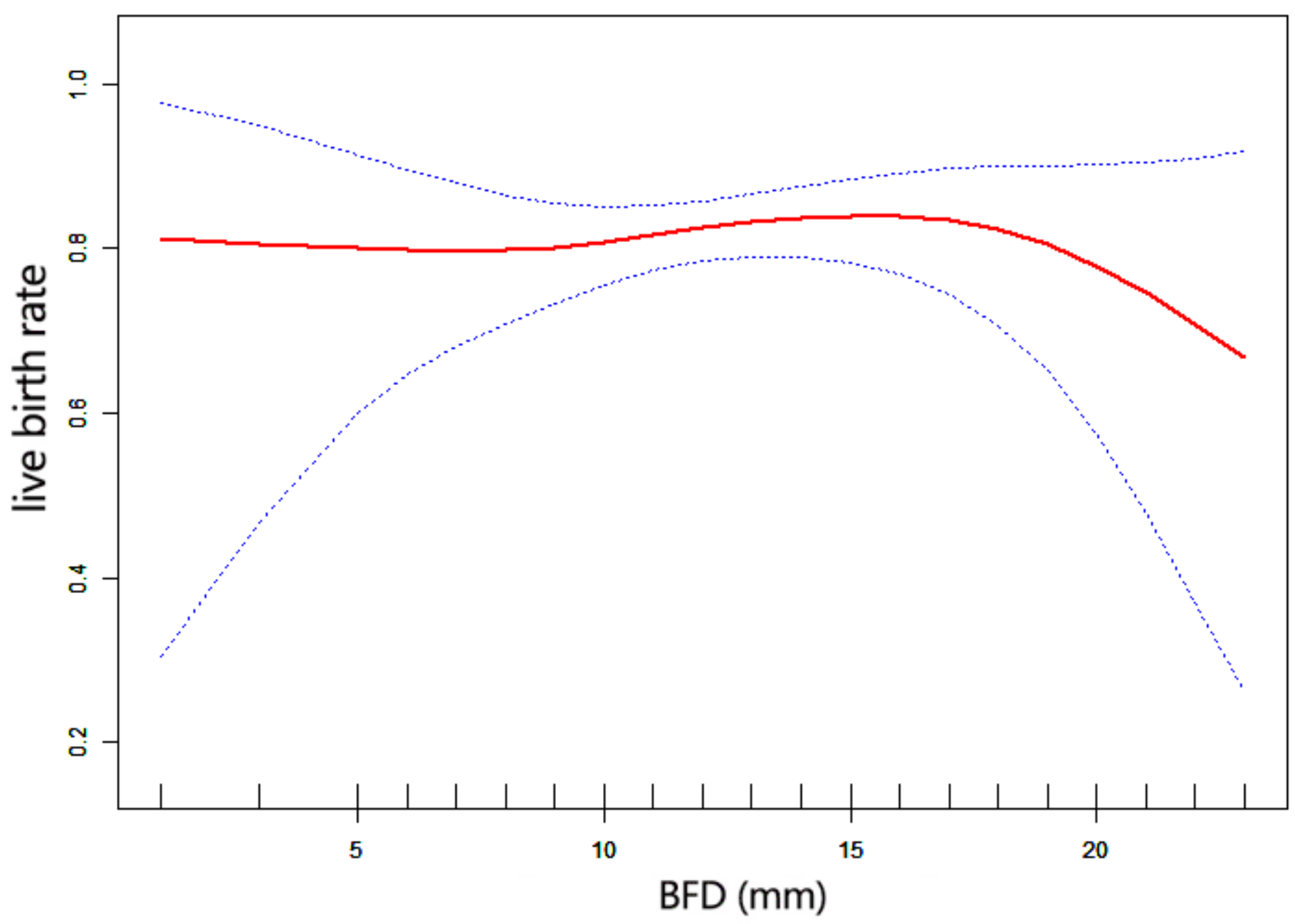

Figure 2

Association between BFD and live birth rate. A threshold, nonlinear association between BFD and live birth rate was found in a generalized additive model (GAM). Solid rad line represents the smooth curve fit between variables. Blue bands represent the $95 \%$ of confidence interval from the fit. All adjusted for age, main cause of infertility, ART ways, times of previous embryo transferred, type of infertility, duration of infertility, BMI, $\mathrm{AMH}$, protocol, endometrial thickness, embryo score and embryo multinucleation. 